\title{
Material Selection in Manufacturing Environment Using Compromise Ranking and Regret Theory-based Compromise Ranking Methods: A Comparative Study
}

\author{
Dipali Rai $^{1}$, Goutam Kumar Jha ${ }^{1}$, Prasenjit Chatterjee ${ }^{1, *}$, Shankar Chakraborty ${ }^{2}$ \\ ${ }^{1}$ Department of Mechanical Engineering, MCKV Institute of Engineering, Liluah, Howrah-711 204, India \\ ${ }^{2}$ Department of Production Engineering, Jadavpur University, Kolkata-700 032, India \\ *Corresponding Author: prasenjit2007@gmail.com
}

Copyright $(\subseteq 2013$ Horizon Research Publishing All rights reserved.

\begin{abstract}
Since decades, proper material selection plays an important and crucial role in an effective manufacturing system for superior production quality, cost optimization and improved productivity. Systematic selection of materials for a given engineering application begins with the study of different material selection properties and their related costs with specific application capabilities. Wrong selection of materials often leads to huge cost contribution and eventually drives an organization towards early product failure. So, the designers need to identify and select proper materials with specific functionalities in order to get the desired output with minimum cost involvement. But, the selection of proper materials for engineering applications is not an easy task to perform. While choosing the proper material for a specific industrial application, there is not always a single definite selection criterion. Designers need to consider a huge number of material selection-attributes and a large number of alternative materials with complex relationships between various attributes. A systematic, efficient and easy approach for material selection is thus required to help the manufacturing organizations for selecting the best material for a particular application. This paper focuses on the application of a compromise ranking method in the perspective of regret theory as a multiple-criteria decision-making (MCDM) tool for solving a material selection problem in a given manufacturing environment. A complete list of all the prospective materials from the best to the worst is obtained, taking into account different material selection attributes. The ranking performance of the proposed method is also compared with that of the original compromise ranking method.
\end{abstract}

Keywords Material Selection, MCDM, Compromise Ranking, Regret Theory, Performance Analysis

\section{Introduction}

Over the centuries, materials play an important and crucial role for a manufacturing system to have value-added production, cost optimization and improved productivity. Material selection is a vital step in the process of designing any physical product/part. Material selection is a process which is performed to select the best material having the potentiality to perform well both industrially and commercially. In the context of product design, the main goal of material selection is to minimize cost while meeting the product performance objectives. Systematic selection of the material for a given application begins with the study of different material properties and the related cost. Failures arising due to bad material selection are not uncommon in the manufacturing industries. Wrong selection of materials frequently leads to huge cost contribution and eventually drives towards untimely product failure. So the designers need to identify and select proper materials with specific functionalities in order to obtain the desired output with minimum cost involvement and specific application ability. However, in the light of manufacturing scenario, selection of material for a particular product is a tedious and time-consuming task to execute, because there are number of factors that have to be carefully evaluated before making the final decision. While choosing the proper material, there is not always a single definite criterion and the designers need to take into account a large number of material selection attributes. The main requirement may be the material strength for designing and manufacturing of a particular mechanical component, but depending on the working environment and functional performance, several other factors may have to be considered simultaneously. Selection of the most suitable material involves the study of a large number mechanical, thermal, electrical and physical properties with consideration of cost, operating environment, production process, market value, availability of supplying sources and product performance. For mechanical design, the mechanical properties of the materials are given the top priorities. The most important mechanical properties that are 
usually encountered in the material selection process are strength, stiffness, toughness, hardness, density and creep resistance. The basic principle of material selection is thus to carefully identify the application requirements, then define the foremost selection criteria and finally, alternative material choices are narrowed down by the method of elimination (screening) and amalgamation of the contradictory criteria [1-3]. MCDM is a logical and systematic way to analyze and evaluate a wide variety of complex decision-making problems in an uncertain environment. MCDM mostly refers to those methods and tools which are generally used for identifying, clearly representing and formally assessing some feasible alternatives which involve quantified evaluations with respect to certain pre-defined criteria. Thus, the material selection can be regarded as a MCDM problem. Hence, a systematic and efficient approach to material selection is required in order to select the best alternative for a given engineering application. The main task lies in comparing the properties of a finite set of materials and selecting the best one out of this set. But while choosing a material for an engineering application, the designers usually apply trial and error methods or employ their knowledge and experience which may fail at any instance. So for selection of materials, an efficient and organized approach is necessary to choose the best material for a particular application to ensure integrity between design, manufacturing objectives, functions, shape, process and materials. Otherwise, the result may be highly susceptible to failure as mentioned earlier. Material property data sheets should never be directly used for the ultimate selection of materials. The actual performance of a particular material under different conditions may differ from the expectations.

\section{Research Reviews on Cutting Edge Techniques for Materials Selection}

For the assessment and selection of suitable materials from the on-hand available alternatives for the given engineering applications, the precedent researchers have developed and presented a number of numerical MCDM approaches and decision support systems. These approaches can be broadly classified as material screening and selection methods. Cost per unit property approach, chart method, questionnaire method, artificial intelligence techniques are the examples of material screening methods. Various MCDM methods and different optimization tools have also been proposed by the past researchers to aid the material selection process.

Tretheway et al. [4] developed a knowledge structure for materials selection based on material performance and failure analysis. Jee and Kang [5] utilized technique for order performance by similarity to ideal solution (TOPSIS) method to short-list alternative materials for a flywheel material selection problem considering several requirements concurrently and employed entropy method to evaluate the weight for each material property. Milani et al. [6] examined the effects of different normalization techniques in TOPSIS method while solving a power transmission gear material selection problem. Rao [7] solved two material selection problems, i.e. for a cryogenic storage tank and for a product designed for operating in a high-temperature oxygen-rich environment using graph theory and matrix approach, and proposed a 'material suitability index' to measure the degree by which a material could be successfully selected for the given engineering design. Shanian and Savadogo [8] applied a non-compensatory compromise approach, namely Elimination And Et Choice Translating Reality (ELECTRE) method for material selection of a bipolar plate to be used in a polymer electrolyte fuel cell. The individual effect of performance indices on material ranking was also studied. Manshadi et al. [9] proposed a novel mathematical method for materials selection based on weighting factor approach combining non-linear normalization with a modified digital logic method. Shanian and Savadogo [10] compared three non-compensatory MCDM methods, e.g. compromise ranking, ELECTRE IS and ELECTRE IV for solving a material selection problem of highly sensitive components involving conflicting and multiple design objectives. Zhou et al. [11] proposed an integration of artificial neural networks with genetic algorithms to optimize the multiple objectives of material selection to develop sustainable products. Rao and Davim [12] used a logical system of material selection for a given engineering design while combining TOPSIS and AHP methods, and proposed a 'material selection index' to help the DM to assess and grade the alternative materials. Chatterjee et al. [13] attempted to solve a flywheel and a sailing boat material selection problems using Vlse Kriterijumska Optimizacija Kompromisno Resenje (VIKOR) and ELECTRE II methods, and compared their relative ranking performance. Khabbaz et al. [14] introduced a simplified fuzzy logic approach to easily deal with the qualitative properties of materials and the corresponding fuzzy space. The proposed approach would considerably reduce the volume of mathematics as involved in the conventional methods. Jahan et al. [15] proposed a multi-criteria method based on linear assignment approach to rank alternative materials for some given engineering applications with respect to several criteria. The proposed material selection procedure was relatively simple and could solve material selection problems having qualitative and quantitative properties. Jahan et al. [16] proposed a new version of VIKOR method with a novel normalization technique based on criteria-to-criteria target values and derived an algorithm with emphasize on compromise solution in material selection. Girubha and Jahan et al. [17] developed a new normalization technique providing an extension of TOPSIS method and objective weighting in materials selection. Four different material selection problems were solved to validate the accuracy of the proposed model. Athawale and Chakraborty [18] applied 10 most commonly used MCDM methods as considered for solving three different material selection problems and 
compared their relative ranking performance. Based on the observations, they concluded that the main focus in material selection should lie on the selection of the relevant criteria and alternatives for subsequent development of the decision matrix, not on the selection of the MCDM method to be adopted. Maity and Chakraborty [19] proposed fuzzy analytic network process (ANP) method for selection of supercritical boiler material and considered seven potential alternatives based on seven material selection attributes. Maity and Chakraborty [20] applied a fuzzy ANP-based approach to select the most appropriate materials for wind energy and wave energy extraction impulse turbine blades. The applicability of the proposed approach was demonstrated with two examples to prove its adaptability to solve such industrial decision-making problems. Jahan [21] proposed a mixed 0-1 goal programming model for simultaneous material selection and design optimization for a biomedical application. The proposed model was justified by ranking the short-listed materials and the results were also compared with the comprehensive VIKOR method. Torrez et al. [22] applied modified digital logic weighting technique along with the weighted sum method to a material selection problem for light-weight naval crafts. Both standard linear and non-linear normalization schemes were applied on a selected set of material properties. A ranking abnormality analysis was conducted to examine the robustness of the selection method. Karande et al. [23] applied two conceptually simple mathematical techniques, i.e. utility concept and desirability function approaches to solve four material selection problems. The proposed approaches were based on the quality characteristic values of the considered material alternatives for arriving at the satisfactory results. Prasad and Chakraborty [24] solved some material selection problems using a quality function deployment-based approach, integrating the voice of the customers for a product with its technical requirements. The applicability and solution accuracy of the proposed approach were demonstrated with the help of four illustrative examples and a user friendly software prototype in Visual BASIC 6.0 was also developed. Chakraborty and Chatterjee [25] solved five material selection problems using TOPSIS, preference ranking organization method for enrichment evaluation (PROMETHEE) and VIKOR methods to demonstrate the effect of number of criteria on the final rankings of the material alternatives. It was observed that the choices of the best suited materials solely depend on the criterion having the maximum priority value. It was also found that among the three considered MCDM methods, VIKOR outperformed the other two methods in terms of the ranking performance.

From the literature survey as presented above, it is observed that an appreciable number of research works has already been performed by the past researchers on materials selection using different MCDM methods, but very little effort has been put till date to compare the relative performance of various MCDM methods while solving the material selection problems. In this research work, a humble effort is taken to balance this space while comparing the ranking performance of the original VIKOR method with respect a regret theory-based VIKOR model while solving a given material selection problem in discrete manufacturing environment. Till date, the proposed regret theory-based VIKOR method has no applications in the material selection domain. One industrial material selection problem is illustrated to demonstrate its applicability and usefulness. It is observed that the proposed regret theory-based VIKOR method has enormous prospects to deal with such complex decision-making problems in conflicting situations.

\section{Compromise Ranking Method}

VIKOR (the Serbian name is 'Vlse Kriterijumska Optimizacija Kompromisno Resenje' which means multi-criteria optimization (MCO) and compromise solution) method was mainly established by Zeleny [26], and later advocated by Opricovic and Tzeng [27-30]. This method is developed to solve MCDM problems with conflicting and non-commensurable (attributes with different units) criteria, assuming that compromise can be acceptable for conflict resolution, when the decision maker wants a solution that is the closest to the ideal solution and the alternatives can be evaluated according to all the established criteria. It focuses on ranking and selecting the best alternative from a set of alternatives with conflicting criteria, and on proposing compromise solution (one or more). The compromise solution is a feasible solution, which is the closest to the ideal solution, and a compromise means an agreement established by mutual concessions made between the alternatives. The following multiple attribute merit for compromise ranking is developed from the $\mathrm{L}_{\mathrm{p}}$-metric as used in the compromise programming method.

$$
\begin{gathered}
\mathrm{L}_{\mathrm{p}, \mathrm{i}}=\left\{\sum_{\mathrm{j}=1}^{\mathrm{M}}\left(\mathrm{w}_{\mathrm{j}}\left[\left(\mathrm{m}_{\mathrm{ij}}\right)_{\max }-\mathrm{m}_{\mathrm{ij}}\right] /\left[\left(\mathrm{m}_{\mathrm{ij}}\right)_{\max }-\left(\mathrm{m}_{\mathrm{ij}}\right)_{\min }\right]\right)^{\mathrm{p}}\right\}^{1 / \mathrm{p}} \\
1 \leq \mathrm{p} \leq \infty ; \mathrm{i}=1,2, \ldots, \mathrm{N}
\end{gathered}
$$

where $\mathrm{M}$ is the number of criteria and $\mathrm{N}$ is the number of alternatives. The $m_{i j}$ values (for $i=1,2, \ldots, N ; j=1,2, \ldots, M$ ) indicate the values of criteria for different alternatives. In the VIKOR method $L_{1, i}$ and $L_{\infty, i}$ are used to formulate the ranking measure.

The procedural steps for the VIKOR method are enlisted as follows:

Step 1: Identify the major material selection criteria for the given problem and short-list alternatives on the basis of the identified criteria satisfying the requirements. A quantitative or qualitative value is assigned to each identified criterion to construct the related decision matrix.

Step 2:

i) After short-listing the alternatives and development of the decision matrix, determine the best, $\left(\mathrm{m}_{\mathrm{ij}}\right)_{\max }$ and the worst, $\left(\mathrm{m}_{\mathrm{ij}}\right)_{\min }$ values of all the criteria. 
ii) The weightings or relative importance of the considered criteria are determined using analytic hierarchy process (AHP) or any other method.

iii) Calculate the $E_{i}$ and $F_{i}$ values of each alternative.

$$
\begin{aligned}
& \mathrm{E}_{\mathrm{i}}=\mathrm{L}_{1, \mathrm{j}}=\sum_{\mathrm{j}=1}^{\mathrm{M}} \mathrm{w}_{\mathrm{j}}\left[\left(\mathrm{m}_{\mathrm{ij}}\right)_{\text {max }}-\mathrm{m}_{\mathrm{ij}}\right] /\left[\left(\mathrm{m}_{\mathrm{ij}}\right)_{\text {max }}-\left(\mathrm{m}_{\mathrm{ij}}\right)_{\text {min }}\right] \\
& \mathrm{F}_{\mathrm{i}}=\mathrm{L}_{\infty, \mathrm{i}}=\operatorname{Max}^{\mathrm{m}} \text { of }\left\{\mathrm{w}_{\mathrm{j}}\left[\left(\mathrm{m}_{\mathrm{ij}}\right)_{\text {max }}-\mathrm{m}_{\mathrm{ij}}\right] /\left[\left(\mathrm{m}_{\mathrm{ij}}\right)_{\max }-\left(\mathrm{m}_{\mathrm{ij}}\right)_{\min }\right]\right\} \\
& \mathrm{j}=1,2, \ldots, \mathrm{M}
\end{aligned}
$$

(2) is applicable to beneficial criteria (where higher values are always desirable for a given application). For non-beneficial criteria (where lower values indicate better performance), $\left[\left(\mathrm{m}_{\mathrm{ij}}\right)_{\max }-\mathrm{m}_{\mathrm{ij}}\right]$ in (2) is to be replaced by $\left[\mathrm{m}_{\mathrm{ij}}-\right.$ $\left.\left(\mathrm{m}_{\mathrm{ij}}\right)_{\min }\right]$. Hence, for non-beneficial criteria, (2) can be rewritten as:

$$
E_{i}=L_{1, j}=\sum_{j=1}^{M} w_{j}\left[\left(m_{i j}\right)-\left(m_{i j}\right)_{\min }\right] /\left[\left(m_{i j}\right)_{\text {max }}-\left(m_{i j}\right)_{\text {min }}\right]
$$

iv) Calculate the compromise index $\left(\mathrm{P}_{\mathrm{i}}\right)$ values as:

$$
\begin{aligned}
\mathrm{P}_{\mathrm{i}}=v\left(\left(\mathrm{E}_{\mathrm{i}}-\mathrm{E}_{\mathrm{i}-\mathrm{min}}\right) /\left(\mathrm{E}_{\mathrm{i}-\max }-\mathrm{E}_{\mathrm{i}-\min }\right)\right)+(1-v)\left(\left(\mathrm{F}_{\mathrm{i}}-\mathrm{F}_{\mathrm{i}-\text { min }}\right) /\right. \\
\left.\left(\mathrm{F}_{\mathrm{i}-\mathrm{max}}-\mathrm{F}_{\mathrm{i}-\mathrm{min}}\right)\right)
\end{aligned}
$$

where $E_{i-\max }$ and $\mathrm{E}_{\mathrm{i}-\mathrm{min}}$ are the maximum and minimum values of $\mathrm{E}_{\mathrm{i}}$ respectively, and $\mathrm{F}_{\mathrm{i}-\max }$ and $\mathrm{F}_{\mathrm{i}-\mathrm{min}}$ are the maximum and minimum values of $\mathrm{F}_{\mathrm{i}}$ respectively. $v$ is introduced as weight of the strategy of 'the majority of attributes' (or 'the maximum group utility'). The value of $v$ lies in the range of 0 to 1 . Normally, the value of $v$ is taken as 0.5 .

v) Arrange the alternatives in the ascending order, according to the values of $\mathrm{P}_{\mathrm{i}}$. Compromise ranking list for a given value of $v$ can be obtained by ranking with the $\mathrm{P}_{\mathrm{i}}$ measure. The best alternative is the one having the minimum $\mathrm{P}_{\mathrm{i}}$ value, if the following two conditions $\left(\mathrm{C}_{1}\right.$ and $\left.\mathrm{C}_{2}\right)$ are satisfied:

$\mathrm{C}_{1}$ : "Acceptable advantage": $\mathrm{P}\left(\mathrm{i}^{\prime \prime}\right)-\mathrm{P}\left(\mathrm{i}^{\prime}\right) \geq \mathrm{DQ}$, where $\mathrm{i}^{\prime}$ is the alternative with second position in the ranking list by $\mathrm{P}_{\mathrm{i}}$ measure value, $\mathrm{DQ}=1 /(\mathrm{N}-1)$.

$\mathrm{C}_{2}$ : "Acceptable stability in decision making": Alternative $i^{\prime}$ must also be the best ranked by $E_{i}$ or/and $F_{i}$ values. This compromise solution is stable within a decision-making process, which could be: "voting by majority rule" (when $v>0.5$ is needed), or "by consensus" $v \approx 0.5$, or "with vote" $(v<0.5)$. If one of the conditions is not satisfied, then a set of compromise solutions is proposed, which consists of

(i) Alternative $i^{\prime}$ and $i^{\prime \prime}$ if only condition $\mathrm{C}_{2}$ is not satisfied, or

(ii) Alternative $i^{\prime}, i^{\prime \prime}, \ldots, i^{(N)}$ if condition $C_{1}$ is not satisfied; and $(\mathrm{N}) \mathrm{a}$ is determined by the relation $\mathrm{P}\left(\mathrm{i}^{(\mathrm{N})}-\mathrm{P}\left(\mathrm{i}^{\prime}\right)\right)$ $<$ DQ for maximum $\mathrm{N}$ (the positions of these alternatives are in closeness).

The VIKOR method is an effective MCDM tool, specifically applicable to those situations when the decision maker is not able, or does not know to express his/her preference at the beginning of the decision-making process. The obtained compromise solution can be accepted by the decision maker as it provides a maximum group utility of the 'majority' and a minimum individual regret of the 'opponent'.

The compromise solutions can be the base for negotiations, involving the decision maker's preference on criteria weights. The VIKOR results depend on the ideal solution, which stands only for a given set of alternatives. Inclusion (or exclusion) of an alternative can affect the VIKOR ranking of the new set of alternatives.

\section{Compromise-regret Theory-based Approach}

Huang et. al. [31] revised the original compromise ranking method with the perspective of regret theory. Regret theory was first proposed by D.E Bell [32] and G. Loomes, R.Sugden, [33]. Regret theory is based upon the fact that human decisions are generally based upon their emotions. These emotions may be mental and psychological thoughts that can be regarded as the main influencing factors in the entire decision-making process. In light of this, Bell [32] and Loome and Sugden [32,33] introduced human feelings of regret, rejoicing, disappointment and elation and proposed a regret model for decision making under uncertain environment. The main concept of regret theory is that the classical utility function is modified by incorporating the anticipated feelings of a decision maker. The main difference between VIKOR and regret theory is that while VIKOR method defines the regret as the difference between the alternatives and the best value of each criterion (discontent utility), regret theory defines the regret as the choiceless utility. In compromise-regret theory-based method, $\mathrm{E}_{\mathrm{i}}$ and $\mathrm{F}_{\mathrm{i}}$ denotes the choiceless and discontent utilities for the $i^{\text {th }}$ alternative respectively and can be defined as:

$$
E_{i}=\left\{\left\|\sum_{j=1}^{M} w_{j} \frac{1}{i-1} \sum_{i=1}^{N}\left(f_{i j}-f_{k j}\right)\right\| \quad \text { if } f_{i j}<f_{k j}, \quad \text { otherwise }=0\right\}
$$

$$
\mathrm{F}_{\mathrm{i}}=\mathrm{L}_{\infty, \mathrm{i}}=\operatorname{Max}^{\mathrm{m}} \text { of }\left\{\mathrm{w}_{\mathrm{j}}\left[\left(\mathrm{m}_{\mathrm{ij}}\right)_{\max }-\mathrm{m}_{\mathrm{ij}}\right] /\left[\left(\mathrm{m}_{\mathrm{ij}}\right)_{\max }-\left(\mathrm{m}_{\mathrm{ij}}\right)_{\min }\right]\right\}
$$$$
j=1,2, \ldots, M
$$

$\|\bullet\|_{p}$ denotes the $L_{p}$-norm. In this paper, $L_{2}$ - norm is used to calculate the $E_{i}$ and $F_{i}$ values of the alternatives. The synthesized compromise-regret index $\left(\mathrm{P}_{\mathrm{i}}\right)$ is then determined as:

$$
\mathrm{P}_{\mathrm{i}}=v\left(\left(\mathrm{E}_{\mathrm{i}}-\mathrm{E}_{\mathrm{i}-\min }\right) /\left(\mathrm{E}_{\mathrm{i}-\max }-\mathrm{E}_{\mathrm{i}-\min }\right)\right)+(1-v)\left(\left(\mathrm{F}_{\mathrm{i}}-\mathrm{F}_{\mathrm{i}-\min }\right) /\right.
$$

The procedure of determining the preference ranking of 
the alternatives is similar to the original VIKOR method.

\section{Illustrative Example}

In order to demonstrate and validate the application of the proposed regret theory-based compromise ranking method for solving material selection problems, the following real time example is illustrated.

Table 1. Quantitative data for flywheel material selection problem [5]

\begin{tabular}{|c|c|c|c|c|}
\hline Sl. No. & $\sigma_{\text {limit }} / \rho$ & $\mathrm{K}_{\mathrm{IC}} / \rho$ & $\mathrm{C} / \mathrm{m}$ & $\mathrm{F}$ \\
\hline $300 \mathrm{M}\left(\mathrm{A}_{1}\right)$ & 100 & 8.6125 & 4200 & 3 \\
\hline $2024-\mathrm{T} 3\left(\mathrm{~A}_{2}\right)$ & 49.6454 & 13.4752 & 2100 & 3 \\
\hline 7050-T73651 $\left(\mathrm{A}_{3}\right)$ & 78.0142 & 12.5532 & 2100 & 3 \\
\hline Ti-6Al-4V $\left(\mathrm{A}_{4}\right)$ & 108.8795 & 26.0042 & 10500 & 3 \\
\hline E glass-epoxy FRP $\left(\mathrm{A}_{5}\right)$ & 70 & 10 & 2735 & 9 \\
\hline S glass-epoxy FRP $\left(\mathrm{A}_{6}\right)$ & 165 & 25 & 4095 & 9 \\
\hline Carbon-epoxy FRP $\left(\mathrm{A}_{7}\right)$ & 440.2516 & 22.0126 & 35470 & 7 \\
\hline Kevlar 29-epoxy FRP $\left(\mathrm{A}_{8}\right)$ & 242.8571 & 28.5714 & 11000 & 7 \\
\hline Kevlar 49-epoxy FRP $\left(\mathrm{A}_{9}\right)$ & 616.4384 & 34.2466 & 25000 & 7 \\
\hline Boron-epoxy FRP $\left(\mathrm{A}_{10}\right)$ & 500 & 23 & 315000 & 5 \\
\hline
\end{tabular}

This example deals with the selection of the most appropriate material for design of a flywheel [5], which is generally used to store kinetic energy. It has vast applications in automobiles, mass transit buses and wind-power generators etc. Despite of its many advantages, it has relatively poor energy storing capacity and also has a probability of catastrophic failure. The main requirements in a flywheel design are to store the maximum amount of kinetic energy per unit mass and to ensure resistance against premature failure due to fatigue or brittle fracture. If the nature of failure is fatigue, the performance index will be $\sigma_{\text {limit }} / \rho$ (where $\sigma_{\text {limit }}$ is the fatigue limit of the material and $\rho$ is the material density). This signifies that the higher the value of $\sigma_{\text {limit }} / \rho$, the lower the weight of the material for a given fatigue strength and consequently, the kinetic energy per unit mass of the flywheel will be higher. For failure due to brittle fracture, fracture toughness $\left(\mathrm{K}_{\mathrm{IC}}\right)$ of the material will be the most important performance measure. If the flywheel breaks into small pieces at final failure, the hazard will be much reduced. Thus, the fragmentability (F) of the material is an important property from the safety point of view. Hence, in this flywheel material selection problem, Jee and Kang [5] considered four selection attributes, namely fatigue limit $\left(\sigma_{\text {limit }} / \rho\right)$, fracture toughness $\left(\mathrm{K}_{\mathrm{IC}} / \rho\right)$, price per unit mass $(\mathrm{C} / \mathrm{m})$ and fragmentability $(\mathrm{F})$. Among these four attributes, fatigue limit, fracture toughness and fragmentability are the beneficial attributes for which higher values are always preferable, while price/mass is a non-beneficial attribute where smaller value indicates better performance of an alternative material. Jee and Kang [5] considered ten alternative materials comprising four metals and six unidirectional fiber-reinforced-epoxy composites. Thus, the flywheel material selection problem consists of 10 alternative materials and 4 material selection attributes, as shown in Table 1.

\subsection{Compromise Ranking Method}

At first, this material selection problem for flywheel design is solved using the original compromise ranking (VIKOR) method. The application of VIKOR method starts by determining the best and the worst values of all the criteria. Jee and Kang [5] employed the entropy method for computing the weights for the considered criteria. They took into account four cases of subjective weighs for the criteria. The first case, where $\mathrm{w}_{\text {бlimit } / \rho}=0.4, \mathrm{w}_{\mathrm{KIC} / \rho}=0.3, \mathrm{w}_{\mathrm{C} / \mathrm{m}}=0.2$ and $\mathrm{w}_{\mathrm{F}}=0.1$, is used here for all the subsequent analysis. Now, the values of $E_{i}$ and $F_{i}$ are calculated using (2) or (4) and (3) respectively, as given in Table 2. This table also exhibits the values of $\mathrm{P}_{\mathrm{i}}$ for $v=0.5$ and the compromise ranking list of the considered alternative materials. The candidate materials are arranged in ascending order, according to the values of $\mathrm{P}_{\mathrm{i}}$. The best choice of material for flywheel design is material $\mathrm{A}_{9}$ (Kevlar 49-epoxy FRP). Carbon-epoxy FRP is the second choice and the last choice is material $\mathrm{A}_{2}$ (2024-T3). Jee and Kang [5] obtained a ranking of the alternative materials as $A_{9}>A_{8}>A_{6}>A_{7}>A_{1}>A_{4}>$ $A_{3}>A_{5}>A_{2}>A_{10}$ using TOPSIS method, whereas, using the VIKOR method, the compromise ranking of materials is obtained as $A_{9}>A_{7}>A_{10}>A_{8}>A_{6}>A_{4}>A_{5}>A_{3}>A_{1}>A_{2}$. It is observed that in both these methods, $A_{9}$ (Kevlar 49-epoxy FRP) evolves out as the best material for the flywheel material selection problem.

Table 2. $\mathrm{E}_{\mathrm{i}}, \mathrm{F}_{\mathrm{i}}$ and $\mathrm{P}_{\mathrm{i}}$ values for example 1

\begin{tabular}{|c|c|c|c|c|}
\hline Material & $\mathrm{E}_{\mathrm{i}}$ & $\mathrm{F}_{\mathrm{i}}$ & $\mathrm{P}_{\mathrm{i}}$ & Rank \\
\hline $\mathrm{A}_{1}$ & 0.7658 & 0.3644 & 0.9515 & 9 \\
\hline $\mathrm{A}_{2}$ & 0.7431 & 0.4000 & 0.9844 & 10 \\
\hline $\mathrm{A}_{3}$ & 0.7339 & 0.3799 & 0.9507 & 8 \\
\hline $\mathrm{A}_{4}$ & 0.5599 & 0.3582 & 0.7356 & 6 \\
\hline $\mathrm{A}_{5}$ & 0.6698 & 0.3856 & 0.9138 & 7 \\
\hline $\mathrm{A}_{6}$ & 0.4280 & 0.3186 & 0.6538 & 5 \\
\hline $\mathrm{A}_{7}$ & 0.3221 & 0.1431 & 0.3408 & 2 \\
\hline $\mathrm{A}_{8}$ & 0.3690 & 0.2636 & 0.5377 & 4 \\
\hline $\mathrm{A}_{9}$ & 0.0479 & 0.0333 & 0 & 1 \\
\hline $\mathrm{A}_{10}$ & 0.4804 & 0.2000 & 0.5287 & 3 \\
\hline
\end{tabular}


Table 3. Ranking of materials for different values of $v$

\begin{tabular}{|c|c|c|c|c|}
\hline Material & $\mathrm{P}_{\mathrm{i}}(v=0)$ & Rank & $\mathrm{P}_{\mathrm{i}}(v=1)$ & Rank \\
\hline $\mathrm{A}_{1}$ & 0.4515 & 7 & 1.4515 & 9 \\
\hline $\mathrm{A}_{2}$ & 0.5000 & 10 & 1.4684 & 10 \\
\hline $\mathrm{A}_{3}$ & 0.4727 & 8 & 1.4282 & 8 \\
\hline $\mathrm{A}_{4}$ & 0.4430 & 6 & 1.1563 & 6 \\
\hline $\mathrm{A}_{5}$ & 0.4804 & 9 & 1.3467 & 7 \\
\hline $\mathrm{A}_{6}$ & 0.3890 & 5 & 0.9185 & 5 \\
\hline $\mathrm{A}_{7}$ & 0.1498 & 2 & 0.5318 & 2 \\
\hline $\mathrm{A}_{8}$ & 0.3141 & 4 & 0.7614 & 3 \\
\hline $\mathrm{A}_{9}$ & 0.0000 & 1 & 0.0000 & 1 \\
\hline $\mathrm{A}_{10}$ & 0.2273 & 3 & 0.8298 & 4 \\
\hline
\end{tabular}

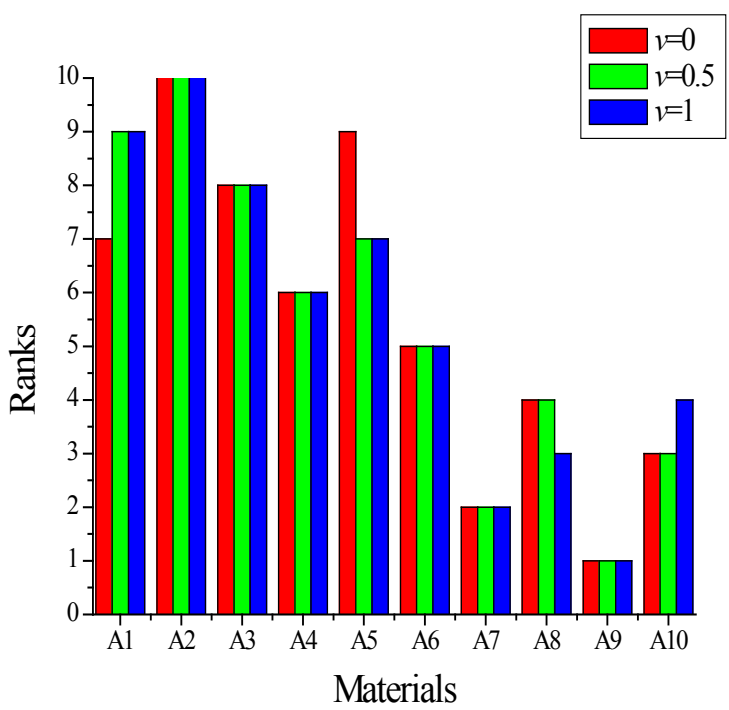

Figure 1. Compromise ranking of materials for different values of $v$

Table 3 and Figure 1 show the comprise rankings of the alternative materials for flywheel design for the two extreme values $v=0$ and $v=1$ as obtained using the original VIKOR method. It is observed that in both the cases, the best choice of material (Kevlar 49-epoxy FRP) does not change, although the ranking of the intermediate materials changes slightly.

\subsection{Regret Theory-based Compromise Ranking Method}

Now, the same problem of selecting the most appropriate material for flywheel design is solved using the proposed compromise-regret theory-based method. At first, the values of $E_{i}$ and $F_{i}$ are calculated using (6) and (7) respectively, as given in Table 4. This table also exhibits the values of the compromise-regret index $\mathrm{P}_{\mathrm{i}}$ for $v=0.5$ and the preference ranking list of the considered alternative materials. The candidate materials are arranged in ascending order of the $P_{i}$ values.

It is observed that material $\mathrm{A}_{9}$ (Kevlar 49-epoxy FRP) emerges out as the best choice for the flywheel design. Carbon-epoxy FRP $\left(\mathrm{A}_{7}\right)$ is the second choice and the last choice is material $A_{1}(300 \mathrm{M})$. It is observed that in the compromise-regret theory-based method, the best choice of material for flywheel design exactly corroborates with that of the original compromise ranking method and also as suggested by Jee and Kang [5].

Table 5 and Figure 2 show the comprise-regret rankings of the considered material alternatives when the two extreme values of $v(v=0$ and $v=1)$ are chosen. It is observed that, material $\mathrm{A}_{9}$ (Kevlar 49-epoxy FRP) remains the best choice for the given flywheel material selection problem for the two extreme values of $v$, thus proving its global acceptability as the best material.

Table 4. $\mathrm{E}_{\mathrm{i}}, \mathrm{F}_{\mathrm{i}}$ and $\mathrm{P}_{\mathrm{i}}$ values using regret theory-based compromise ranking method

\begin{tabular}{|c|c|c|c|c|}
\hline Material & $\mathrm{E}_{\mathrm{i}}$ & $\mathrm{F}_{\mathrm{i}}$ & $\mathrm{P}_{\mathrm{i}}$ & Rank \\
\hline $\mathrm{A}_{1}$ & 0.3167 & 0.3645 & 0.9515 & 10 \\
\hline $\mathrm{A}_{2}$ & 0.2451 & 0.4000 & 0.8833 & 7 \\
\hline $\mathrm{A}_{3}$ & 0.2855 & 0.3800 & 0.9219 & 9 \\
\hline $\mathrm{A}_{4}$ & 0.1762 & 0.3582 & 0.7140 & 6 \\
\hline $\mathrm{A}_{5}$ & 0.2673 & 0.3856 & 0.8999 & 8 \\
\hline $\mathrm{A}_{6}$ & 0.1077 & 0.3186 & 0.5484 & 4 \\
\hline $\mathrm{A}_{7}$ & 0.0765 & 0.1432 & 0.2584 & 2 \\
\hline $\mathrm{A}_{8}$ & 0.0826 & 0.2636 & 0.4326 & 3 \\
\hline $\mathrm{A}_{9}$ & 0.0098 & 0.0333 & 0.0000 & 1 \\
\hline $\mathrm{A}_{10}$ & 0.2579 & 0.2000 & 0.6314 & 5 \\
\hline
\end{tabular}

Table 5. Ranking of flywheel materials for different values of $v$

\begin{tabular}{|c|c|c|c|c|}
\hline Material & $\mathrm{P}_{\mathrm{i}}(v=0)$ & Rank & $\mathrm{P}_{\mathrm{i}}(v=1)$ & Rank \\
\hline $\mathrm{A}_{1}$ & 0.4515 & 7 & 1.4515 & 10 \\
\hline $\mathrm{A}_{2}$ & 0.5000 & 10 & 1.2667 & 7 \\
\hline $\mathrm{A}_{3}$ & 0.4727 & 8 & 1.3711 & 9 \\
\hline $\mathrm{A}_{4}$ & 0.4430 & 6 & 0.9851 & 5 \\
\hline $\mathrm{A}_{5}$ & 0.4804 & 9 & 1.3194 & 8 \\
\hline $\mathrm{A}_{6}$ & 0.3890 & 5 & 0.7079 & 4 \\
\hline $\mathrm{A}_{7}$ & 0.1498 & 2 & 0.3669 & 2 \\
\hline $\mathrm{A}_{8}$ & 0.3141 & 4 & 0.5511 & 3 \\
\hline $\mathrm{A}_{9}$ & 0.0000 & 1 & 0.0000 & 1 \\
\hline $\mathrm{A}_{10}$ & 0.2273 & 3 & 1.0356 & 6 \\
\hline
\end{tabular}




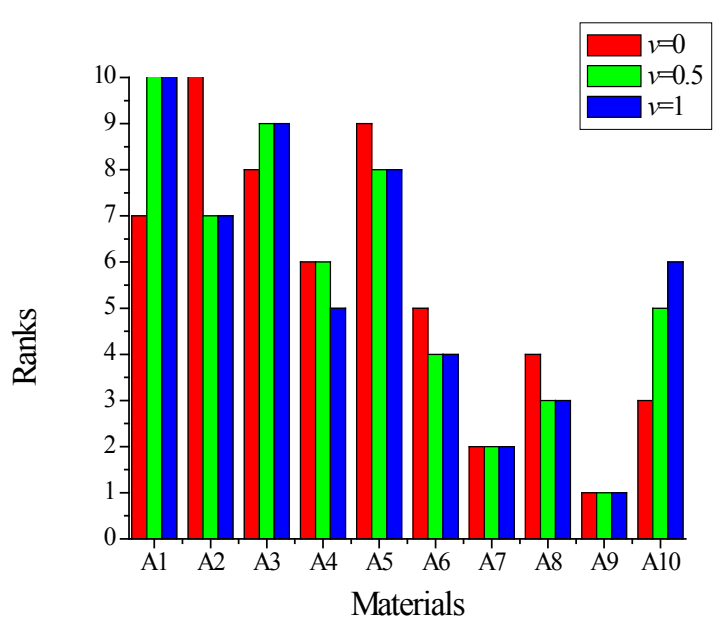

Figure 2. Compromise-regret ranking of materials for different values of $v$

\section{Performance Analysis}

Now in order to compare the relative performance and examine the level of rank conformity between the results as produced by the original VIKOR method and regret theory-based VIKOR method with respect to TOPSIS method as adopted by Jee and Kang [5] while solving this flywheel material selection problem, the following four tests are performed. The performance measures in the evaluation matrices are kept unchanged during these tests. It is observed that although there are some deviations in the rankings of the intermediate materials due to different mathematical treatments involved in these methodologies, still, Kevlar 49-epoxy FRP $\left(\mathrm{A}_{9}\right)$ evolves out as the best choice in all of the considered methods. Table 6 summarizes the ranking preorders of the alternative flywheel materials as derived from the considered MCDM methods.

Table 6. Ranking preorders obtained from different MCDM methods

\begin{tabular}{|c|c|c|c|}
\hline Material & TOPSIS [5] & VIKOR & $\begin{array}{c}\text { Regret theory-based } \\
\text { VIKOR }\end{array}$ \\
\hline $\mathrm{A}_{1}$ & 5 & 9 & 10 \\
\hline $\mathrm{A}_{2}$ & 9 & 10 & 7 \\
\hline $\mathrm{A}_{3}$ & 7 & 8 & 9 \\
\hline $\mathrm{A}_{4}$ & 6 & 6 & 6 \\
\hline $\mathrm{A}_{5}$ & 8 & 7 & 8 \\
\hline $\mathrm{A}_{6}$ & 3 & 5 & 4 \\
\hline $\mathrm{A}_{7}$ & 4 & 2 & 2 \\
\hline $\mathrm{A}_{8}$ & 2 & 4 & 3 \\
\hline $\mathrm{A}_{9}$ & 1 & 1 & 1 \\
\hline $\mathrm{A}_{10}$ & 10 & 3 & 5 \\
\hline
\end{tabular}

a) In the first test, the overall ranking agreement among all the three methods is determined using the Kendall's coefficient of concordance $(\mathrm{z})$ value. In this case, $\mathrm{z}$ value is obtained as 0.76 , indicating an almost superior rank conformity between the three methods.

b) In the second test, the Spearman's rank correlation coefficient (rs) values are calculated to compare the rankings of the alternative flywheel materials obtained using different methods between themselves and also with respect to the rank orderings derived by Jee and Kang [5] using TOPSIS method. From Table 7, it is observed that the regret theory-based compromise ranking method shows better performance as compared to the original compromise ranking method in terms of rank correlation. Figure 3 shows the Spearman rank correlation coefficients for these two methods for different values of $\mathrm{v}$ with respect to the TOPSIS method [5].

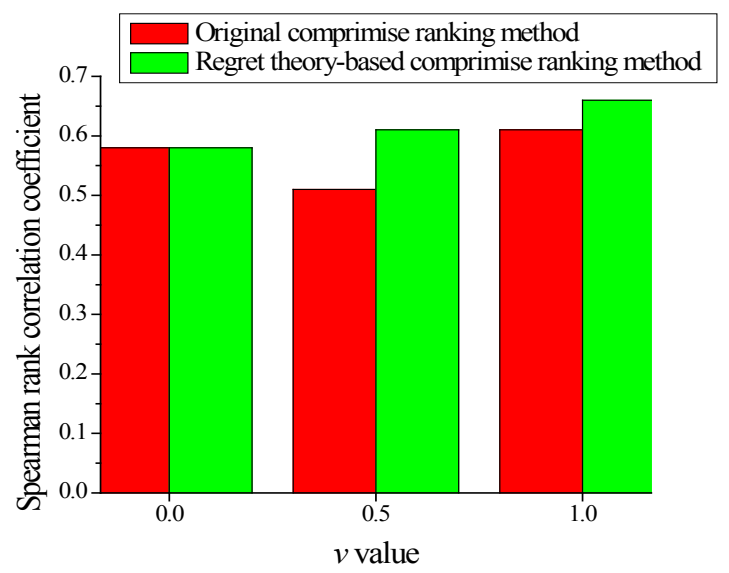

Figure 3. Spearman rank correlation coefficients for different values of $v$

c) The third test is based on the agreement between the top three ranked material alternatives as indicated by these methods. Table 7 again exhibits that both the compromise ranking methods show similar ranking performances with respect to TOPSIS method employed by Jee and Kang [5]. d) The last test is performed to determine the overall percentage of ranks matched between the three considered methods, it is again observed from Table 7 that the regret theory-based compromise ranking method shows higher percentage of rank matches with respect to TOPSIS method.

Table 7. Performance test table for MCDM methods

\begin{tabular}{|c|c|c|}
\hline Method & $\begin{array}{c}\text { Compromise } \\
\text { ranking }\end{array}$ & $\begin{array}{c}\text { Regret theory-based } \\
\text { compromise ranking }\end{array}$ \\
\hline TOPSIS [5] & $\begin{array}{c}0.51 \\
(1, \#, \#, 20)\end{array}$ & $\begin{array}{c}0.61 \\
(1, \#, \#, 33.33)\end{array}$ \\
\hline $\begin{array}{c}0.89 \\
\text { Regret theory-based } \\
\text { compromise ranking }\end{array}$ & $\begin{array}{c}0.59-0.97] \\
(1,2, \#, 33.33)\end{array}$ \\
\hline
\end{tabular}

\section{Conclusion and Discussion}

The original compromise ranking or VIKOR method was basically introduced as an MCDM tool based on the particular measure of closeness to the ideal solution using a 
linear normalization technique. VIKOR method focuses on selecting the best alternative from a set of feasible alternatives in the presence of communally conflicting criteria by determining a compromise solution. It provides a maximum group utility for the "majority", and a minimum of individual regret for the "opponent' both'. The major problem of the original VIKOR method is that it may derive wrong preference ranking of the considered alternatives due of the complicated computations of $E_{i}$ and $F_{i}$ values. More specifically, the normalization of the $E_{i}$ and $F_{i}$ values result in the levels of regrets which are influenced by the worst values of the considered criteria. However, according to the perspective of regret theory, the levels of regret are only affected by the best values of criteria. On the other hand, regret theory also proposes that the level of regret comes from the choiceless utility. In this paper, an attempt is made to compare the ranking performances of the original VIKOR model with the regret theory-based VIKOR method to consider both the choiceless and discontent utilities. From the above cited flywheel material selection problem, it is observed that the regret theory-based VIKOR method shows relatively better performance as compared to the original VIKOR method.

\section{REFERENCES}

[1] L.Y. Ljungberg. Materials selection and design for development of sustainable products, Materials \& Design, Vol.28, No.2, 466-479, 2007.

[2] K.L. Edwards. Selecting materials for optimum use in engineering components, Materials \& Design, Vol. 26, No.5, 469-472, 2005.

[3] L.Y. Ljungberg, K.L. Edwards. Design, materials selection and marketing of successful products, Materials \& Design, Vol.24, No.7, 519-529, 2003.

[4] K.R. Tretheway, R.J.K. Wood, P.R. Roberge. Development of a knowledge-based system for materials management. Materials \& Design, Vol.19, No.1, 39-56, 1998.

[5] D-H. Jee, K-J. Kang. A method for optimal material selection aided with decision making theory, Materials \& Design, Vol.21, No.3, 199-206, 2000.

[6] A.S. Milani, A. Shanian, R. Madoliat, J.A. Nemes. The effect of normalization norms in multiple attribute decision making models: a case study in gear material selection, Structural and Multidisciplinary Optimization, Vol.29, No.4, 312-318, 2005.

[7] R.V. Rao. A material selection model using graph theory and matrix approach. Material Science and Engineering A, Vol.431, No.1-2, 248-255, 2006.

[8] Shanian, A. and Savadogo, O. A non-compensatory compromised solution for material selection of bipolar plates for polymer electrolyte membrane fuel cell (PEMFC) using ELECTRE IV, Electrochimica Acta, Vol.51, No.25, $5307-5315,2006$
[9] B.D. Manshadi, H. Mahmudi, A. Abedian, R. A. Mahmudi. A novel method for materials selection in mechanical design: combination of non-linear linearization and a modified digital logic method, Materials \& Design, Vol.28, No.8, 8-15, 2007.

[10] A. Shanian, O. Savadogo. A methodological concept for material selection of highly sensitive components based on multiple criteria decision analysis, Expert Systems with Application, Vol.36, No.2, 1362-1370, 2009.

[11] C.C. Zhou, G. F. Yin, X.B. Hu. Multi-objective optimization of material selection for sustainable products: artificial neural networks and genetic algorithm approach, Materials \& Design, Vol.30, No.4, 1209-1215, 2008.

[12] R.V. Rao, J. P. Davim. A decision-making framework model for material selection using a combined multiple attribute decision-making method, International Journal of Advanced Manufacturing Technology, Vol.35, No.7-8, 751-760, 2008.

[13] P. Chatterjee, V.M. Athawale, S. Chakraborty. Selection of materials using compromise ranking and outranking methods, Materials \& Design, Vol.30, No.10, 4053-4063, 2009.

[14] R.S. Khabbaz, B.D. Manshadi, A. Abedin, R. A. Mahmudi. simplified fuzzy logic approach for materials selection in mechanical engineering design, Materials \& Design, 30, No.3, 687-697, 2009.

[15] A Jahan, M.Y. Ismail, F. Mustapha, S.M. Sapuan. Material selection based on ordinal data, Materials \& Design, Vol.31, No.7, 3180-3187, 2010.

[16] A. Jahan, F. Mustapha, Md. Y. Ismail, S.M. Sapuan, M. Bahraminasab. A comprehensive VIKOR method for material selection, Materials \& Design, Vol.32, No.3, 1215-1221, 2011.

[17] A. Jahan, M. Bahraminasab, K.L. Edwards. A target-based normalization technique for materials selection, Materials \& Design, Vol.35, 647-654, 2012.

[18] V.M. Athawale, S. Chakraborty. Material selection using multi-criteria decision-making methods: A comparative study, Proc. of Institution of Mechanical Engineers, Part L, Journal of Materials: Design and Applications, Vol.226, No.4, 267-286, 2012.

[19] S.R. Maity, S. Chakraborty. Supercritical boiler material selection using fuzzy analytic network process, Management Science Letters, Vol.2, No.4, 1083-1096, 2012.

[20] S.R. Maity, S. Chakraborty. Turbine blade material selection using fuzzy analytic network process, International Journal of Materials and Structural Integrity, Vol.6, No.2-4, 169-189, 2012.

[21] A Jahan. Material selection in biomedical applications: comparing the comprehensive VIKOR and goal programming models, International Journal of Materials and Structural Integrity, Vol.6, No.2/3/4, 230-240, 2012.

[22] J.B. Torrez, A.S. Milani, D.D.C. Sachuetze. Material selection for light-weight naval crafts using the modified digital logic method: dealing with ranking abnormalities, International Journal of Materials and Structural Integrity, Vol.6, No.2-4, 241-256, 2012.

[23] P. Karande, S.K. Gauri, S. Chakraborty. Applications of utility concept and desirability function for materials selection, Materials \& Design, Vol.45, 349-358, 2013. 
[24] K. Prasad, S. Chakraborty. A quality function deployment-based model for materials selection, Materials \& Design, Vol.49, 525-535, 2013.

[25] S. Chakraborty, P. Chatterjee. Selection of materials using multi-criteria decision-making methods with minimum data, Vol. 2, No. 3, 135-148, 2013.

[26] M. Zeleny. Multiple criteria decision making, McGraw Hill, New York, 2002.

[27] S. Opricovic, G.H. Tzeng. Multi criteria planning of post-earthquake sustainable reconstruction, Computer Aided Civil Infrastructure Engineering, Vol.17, No.3, 211-220, 2002.

[28] S. Opricovic, G.H. Tzeng. Fuzzy multi criteria model for post-earthquake land-use planning, Natural Hazards Review, Vol.4, No.2, 59-64, 2003.

[29] S. Opricovic, G.H. Tzeng. Compromise solution by MCDM methods: a comparative analysis of VIKOR and TOPSIS, European Journal of Operational Research, Vol. 156, No.2, 445-455, 2004.
[30] S. Opricovic, G.H. Tzeng. Extended VIKOR method in comparison with outranking methods. European Journal of Operational Research, Vol.178, No.2, 514-529, 2007.

[31] J.J. Huang, G.H. Tzeng, H.H. Liu. A Revised VIKOR Model for Multiple Criteria Decision Making - The Perspective of Regret Theory, Cutting-Edge Research Topics on Multiple Criteria Decision Making, Communications in Computer and Information Science, Vol. 35, 761-768, 2009.

[32] D.E. Bell. Regret in decision making under uncertainty, Operations Research, Vol.30, No.5, 961-981, 1982.

[33] G. Loomes, R. Sugden. Regret theory: an alternative theory of rational choice under uncertainty, The Economic Journal, Vol.92, No.368, 805-824, 1982.

[34] G. Loomes, R. Sugden. Disappointment and dynamic consistency in choice under uncertainty, Review of Economic Studies, Vol.53, No.2, 271-282, 1986 